\title{
Favipiravir tautomerism: a theoretical insight
}

\author{
Liudmil Antonov ${ }^{1}$ (B)
}

Received: 5 June 2020 / Accepted: 23 July 2020 / Published online: 10 August 2020

(c) Springer-Verlag GmbH Germany, part of Springer Nature 2020

\begin{abstract}
There is no experimental information about the tautomerism of Favipiravir (T-705). Therefore, its tautomeric state was predicted by using density functional theory in gas phase and in solution (toluene, acetonitrile and water). The results have shown that, in neutral state, the enol form is strongly dominating in both gas phase and solution. The carboxamide group is easily protonated in the presence of acid, which leads to shift of the tautomeric equilibrium toward the keto tautomer. In order to validate the theoretical predictions, 2-hydroxy pyridine and 2-hydroxy pyrazine were also included in the set of studied compounds. The available experimental data about their tautomerism are in very good agreement with the theoretical predictions, which validate the conclusions made for T-705.
\end{abstract}

Keywords T-705 $\cdot$ Avigan $\cdot$ Favilavir $\cdot$ Favipiravir $\cdot$ COVID-19 $\cdot$ Tautomerism $\cdot$ Density functional calculations

\section{Introduction}

According to the UIPAC definition [1], tautomerism is "Isomerism of the general form:

$G-X-Y=Z \rightleftarrows X=Y-Z-G$

where the isomers (called tautomers) are readily interconvertible; the atoms connecting the groups $X, Y$, and $Z$ are typically any of $\mathrm{C}, \mathrm{N}, \mathrm{O}$, or $\mathrm{S}$, and $\mathrm{G}$ is a group that becomes an electrofuge or nucleofuge during isomerization. The commonest case, when the electrofuge is $\mathrm{H}^{+}$, is also known as prototropy."

Although the prototropic tautomerism can occur (really or potentially) in relatively limited number of molecules, it is one of the important phenomena in organic chemistry in respect of the property and reactivity [2]. The interconvertivity is the major difference with the other types of isomers: enantiomers, or cis and trans isomers, for instance, also possess a formulaic identity just as tautomers do, but are difficult to interconvert, which allows physically to be isolated. Tautomers have chameleonic nature in most of the cases. They are able to switch from one, well-known,

Liudmil Antonov

liudmil.antonov@gmail.com

http://www.tautomer.eu

1 Institute of Electronics, Bulgarian Academy of Sciences, 1784 Sofia, Bulgaria structure to another following the changes in the local environment, and then to return back, when original conditions are restored. The transfer of the proton from one place of the molecule to another dramatically changes the electronic structure and, hence, variety of properties. As a result, the tautomeric forms differ in shape, functional groups, surface, and hydrogen bonding pattern.

Biological activity is one of the properties that are heavily affected by the proton transfer. The vital importance of knowing the tautomeric state in various aspects of the drug design has been underlined by many authors [3-7]. Martin [4] wrote recently that about $21 \%$ of molecules in various drug discovery databases are potentially tautomeric [8-10], and it is crucially important to know the exact tautomeric state in the different stages of the drug design.

Favipiravir (also known as T-705, Avigan, Favilavir, Scheme 1) is an antiviral drug [11-14], developed by FUJIFILM Toyama Chemical Co (http://fftc.fujifilm.co.jp/en/di/ pipeline/index.html) [15]. Along with other experimental antiviral drugs (T-1105 and T-1106) [11], it belongs to the pyrazine carboxamide family. According to the results of clinical studies, T-705 revealed activity against influenza viruses, West Nile virus, yellow fever virus, foot-and-mouth disease virus, as well as other flaviviruses, arenaviruses, bunyaviruses, and alphaviruses [11,12]. Recently, the same drug has shown promising results in the treatment of the severe acute respiratory syndrome coronavirus 2 (SARSCoV-2) in China [16-20]. 


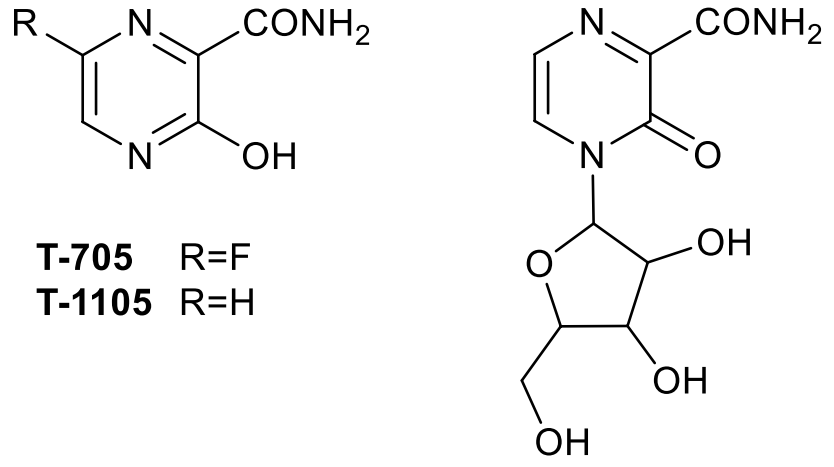

T-1106

Scheme 1 Compounds in the current study<smiles>[R]c1[X]c([R])c(O)nc1</smiles>

enol form $(E)$<smiles>[R]c1[X]c([R])c(=O)[nH]c1</smiles>

keto form (K)
Scheme 2 Tautomerism of the studied compounds

As seen from Scheme 1, T-705, as well as its analogues (T-1105 and T-1106), belong to the potentially tautomeric 2-hydroxy pyrazine family. The studies of the mechanism of action of T-705 revealed its activity as a nucleobase analogue [21]. It is converted into the ribonucleoside triphosphate intracellularly and ultimately acts on the viral RNAdependent RNA polymerase [22-24]. The T-705 and T-1105 ribonucleosides [25] are nothing else than fixed keto tautomeric forms as T-1106 actually is.

At this moment of urgent need for COVID-19 treatment solutions, any additional information, including tautomeric one, about this family of compounds, could be useful. The experimental investigations of the tautomerism of T-705 will be performed in future for sure, but in the current communication, the potential of theoretical chemistry will be used to predict the tautomeric state of favipiravir and the effects of substitution in the pyrazine ring. Such study is not unrelated to reality, because there is sufficient number of experimental and theoretical data for the tautomerism of structurally similar compounds, which can be used to validate the theoretical predictions.

\section{Results and discussion}

The tautomeric equilibrium in the studied compounds is sketched in Scheme 2. Strictly speaking, this is lactim-lactam tautomerism, but for simplicity in the discussion below, enol and keto tautomers will be used. The corresponding stabilities of the tautomers are collected in Table 1 in gas phase and in three solvents with different polarity. Taking into account that implicit solvation is used to describe the solvent effect, the results in the table has to be considered only in the light of the relative stabilization of the more polar tautomer, i.e., the expected specific solute-solvent interactions are not accounted in water. Logically, the increased dielectric constant of the solvents, from toluene to water, leads to relative stabilization of the more polar keto form in each of the listed compounds.

Having in mind that the relative stability of the tautomers strongly depends on the used level of theory, selected basis set and the solvent description, reference compounds, for which reliable experimental data are available, are needed to validate the overall approach. The tautomerism of both, T-705 and T-1105, has never been studied experimentally before. Therefore, $\mathbf{1}$ and $\mathbf{2}$, having the same tautomeric backbone, are included in the set in order to clarify the reliability of the theoretical predictions.

As seen, in the case of 2-hydroxy pyridine (1), the enol form is more stable in gas phase ( $90 \%)$, while going to a condensed phase its fraction is reduced from $\sim 20 \%$ in toluene to a negligible amount in the rest of the solvents. The replacement of the carbon atom with nitrogen in $\mathbf{2}$ leads to destabilization of the keto tautomer. The results suggest that the equilibrium is almost fully shifted toward $\mathbf{2 E}$ in gas phase, and following the same trend as in $\mathbf{1}$, the increased solvent polarity stabilizes $\mathbf{2 K}$. Fluorine substitution in $\mathbf{3}$ and a carboxamide group in T-1105 leads to a further stabilization of the enol tautomers. Both effects are accumulated in T-705 suggesting that the keto tautomer is not likely to be experimentally observed. This conclusion agrees with the recent calculations of da Silva [26], performed at a different level of theory. There is a detail in T-1105 and T-705, which should be taken into account. The tautomeric proton in the enol form is a part of a strong intramolecular hydrogen bonding, while the $\mathrm{NH}$ proton in the keto form is available for interaction with proton acceptor solvents like water. Additional stabilization of the keto tautomer, where two neighbor carbonyl groups are present, can be achieved also by a complexation with metal ions. This could change the tautomeric state, but only further experiments can prove or not such expectations. It should be noted that some recent cases of tautomerism of drugs (curcumin [27] and piroxicam [28]) show that theoretically unfavored tautomers can be stabilized in water as a result of specific interactions.

The keto-enol tautomerism of 2-hydroxy pyridine (1) is one of the most studied tautomeric cases, both theoretically and experimentally. Very detailed description of the effects of the used level of theory can be found in [7, 29, 30]. For gas phase, most of the density functionals overestimate (some of them very strongly) the keto form stability, while 
Table 1 Relative energies* at M06-2X/def2TZVP level of theory (TautLYP/6-31++Gdp in the brackets) of the tautomers of the studied compounds (see Scheme 2)

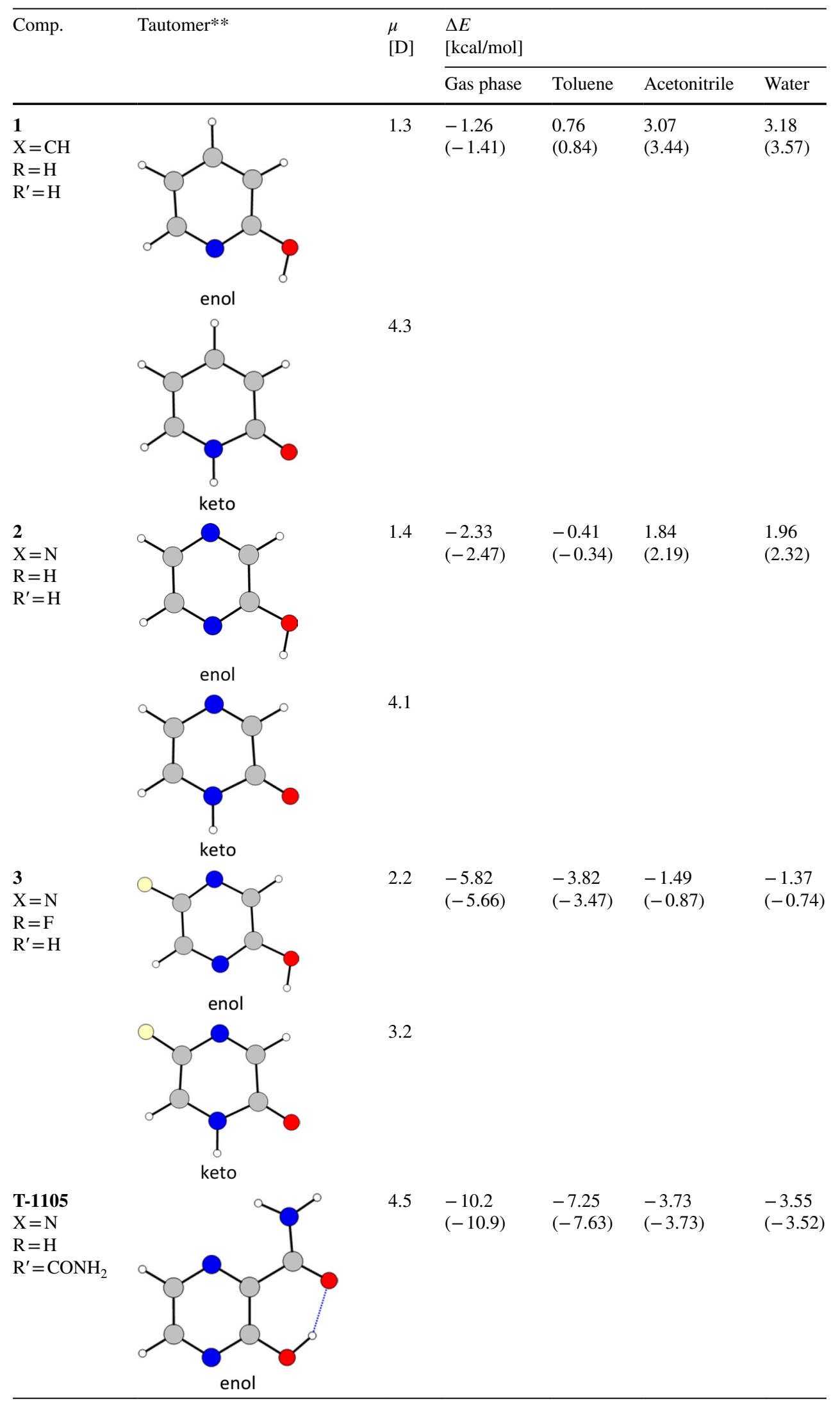


Table 1 (continued)

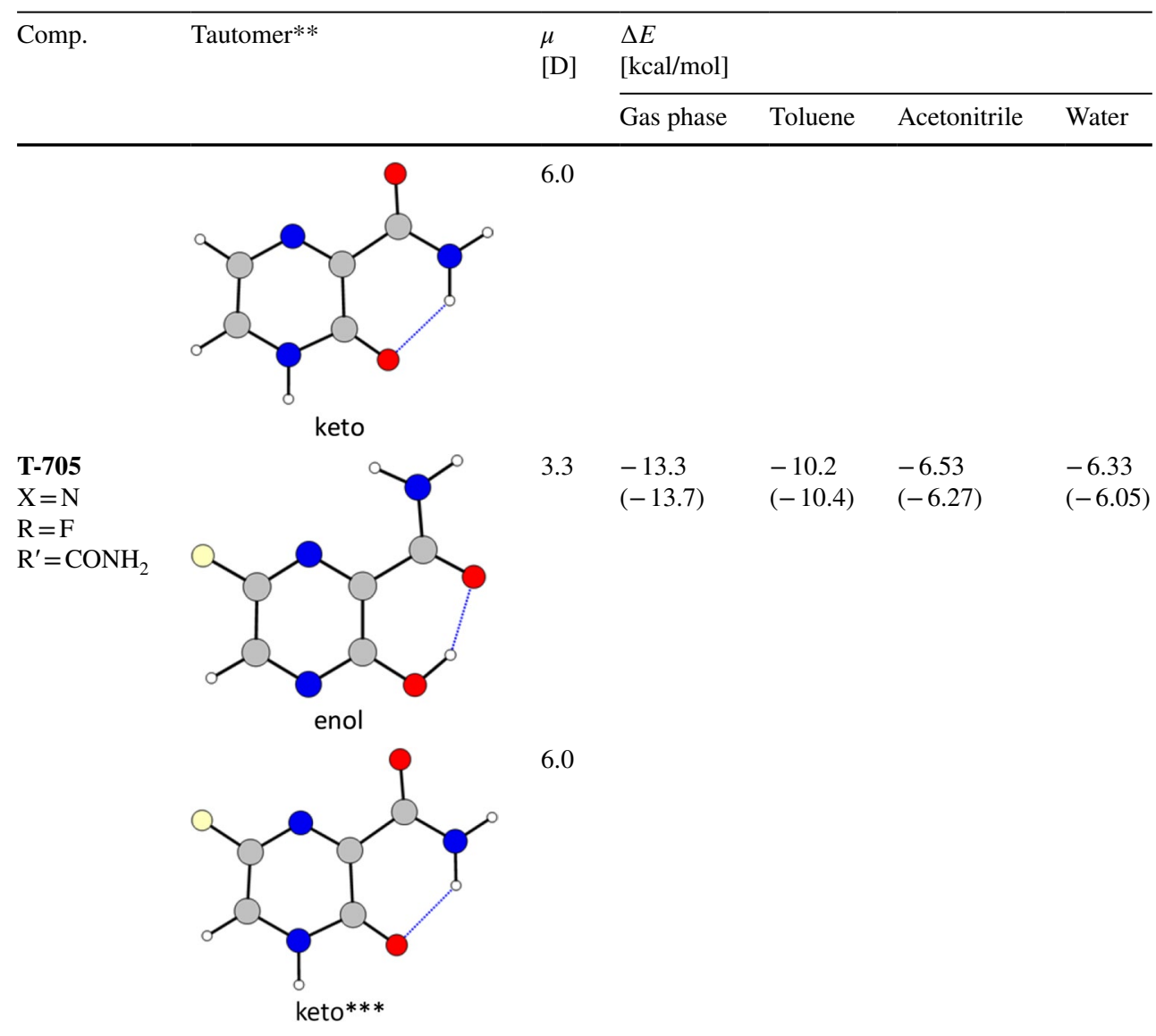

*Difference between the total energies of the enol and keto forms $\left(\Delta E=E_{\mathrm{E}}-E_{\mathrm{K}}\right)$, negative value indicates more stable enol form and vice versa

**Presented as the most stable isomer

*** Orientation of the $\mathrm{CONH}_{2}$ group corresponds exactly to the crystal structure of $\mathbf{T}-\mathbf{7 0 5}$-ribonucleoside as reported in [25]

HF and post-HF methods predict more, but not dramatically, stable 1E. Fortunately, there are experimental data to compare. The $\Delta G^{\mathrm{o}}$ value has been estimated, in $\mathrm{kcal} / \mathrm{mol}$ units, by variety of techniques and at different temperatures as follows: - 0.8 (573 K, IR spectroscopy [31]; $412 \mathrm{~K}$, UV spectroscopy [32]), -0.57 (403 K, X-ray photoelectron spectroscopy) [33], -0.88 (323 K, photoelectron spectroscopy) [34], -0.87 (360 K, IR matrix-isolated technique) [35] and -0.77 (356 K, microwave spectroscopy) [36]. The decrease in the temperature leads to elevation of the enol form content from $68 \%$ [37] at $473 \mathrm{~K}$ to $80 \%$ at $323 \mathrm{~K}$ [34]. In this respect, the prediction of $90 \%$ for $\mathbf{1} \mathbf{K}$ at room temperature, as shown in Table 1, is very reasonable. Even at $\operatorname{CCSD}(\mathrm{T}) /$ def2TZVP level of theory, the stability of the enol form is slightly overestimated in respect of the experiment, predicting $\Delta \mathrm{E}$ values of $-1.2 \mathrm{kcal} / \mathrm{mol}$ [38]. It is worth to underline that the estimation of the relative stability of the tautomers in gas phase is based, in some of the cases, on assumption that both tautomers have equal individual responses (UV/IR individual intensity, ionization cross section, etc.). This is a common problem in spectroscopy when tautomeric equilibria are investigated, because the individual tautomers cannot be isolated, and hence, their individual responses are unknown. Details about possible assumptions and deviations of the results can be found in $[39,40]$. Returning back to the classical work of Beak and Fry [32], the tautomeric ratio was determined in the range 393-412 K by means of gasphase UV spectroscopy. In this particular case, the tautomeric fractions were estimated using the intensities of the $\mathrm{O}$ and $\mathrm{N}$ methylated compounds (so-called fixed tautomers) as individual responses of the pure tautomers, which makes the approach physically reliable $[2,40]$. The estimated enol fractions are in the range $50-80 \%(2.5 \pm 1.5 / 1$ ratio of $\mathbf{1 E} / \mathbf{1 K})$, which leads a $\Delta G^{\mathrm{o}}$ value varying from 0 to $-1.1 \mathrm{kcal} / \mathrm{mol}$.

The data for the tautomerism of $\mathbf{1}$ in solution are also helpful in validating the approach. Such information is available for cyclohexane [41, 42], carbon tetrachloride [43] and acetonitrile [42], determined by UV spectroscopy and methylated compounds as references. The corresponding $\Delta G^{\mathrm{o}}$ values are $0.3,1.3$ and $2.7 \mathrm{kcal} / \mathrm{mol}$ respectively, which 
indicates predominance of the keto tautomer as predicted by the calculations. The results for water are approximate (based on the pKa approximation $[42,44,45]$ ) and indicate a ratio $\mathbf{1 E} / \mathbf{1 K}<1 / 900$, i.e., the equilibrium is practically switched toward the keto tautomer.

Comparing to $\mathbf{1}$, in the case of $\mathbf{2}$, less experimental data are available. By using IR matrix-isolated technique, $\Delta G^{\mathrm{o}}$ values were estimated as follows: $-1.55 \pm 0.11(360 \mathrm{~K})$ [35] and $-1.85 \pm 0.24(360 \mathrm{~K})[46] \mathrm{kcal} / \mathrm{mol}$, confirming that the enol form strongly dominates in gas phase. The stabilization of the enol in $\mathbf{2}$ is larger comparing to $\mathbf{1}$, as the calculations suggest. It was shown in DMSO by NMR that the $\mathbf{2 K}$ form is dominating [47].

The experimental data for $\mathbf{1}$ and $\mathbf{2}$ confirm the predicted effects of the solvent environment and the structural changes on the tautomerism in the studied heterocycles. Therefore, we can assume that the theoretical predictions should be correct in the case of the other compounds for which there are no experimental data available. It should be expected that the neutral T-1105 and T-705 with high probability exist as enol tautomers in most of the organic solvents and water.

T-705 is an orally administered drug and some aspects of the drug-delivery process should be taken into account when the tautomerism is discussed. The dissolution takes place in the stomach at $\mathrm{pH} \sim 1$, which leads to protonation. In Table 2 the relative stabilities of the most stable protonated forms are collected. The data clearly indicate that the $\mathrm{CO}$ group from carboxamide is a preferred protonation site (KE is the only exception, which will be discussed below), which change leads to the change in the tautomeric state. The other protonation scenarios lead to structures with relative stability of 10 and more $\mathrm{kcal} / \mathrm{mol}$ in gas phase. As seen from the Table, in gas phase a mixture of structures with similar stabilities is possible, while with increasing solvent polarity it becomes evident that the protonated keto tautomer $\mathbf{K 1}$ becomes the most stable one. From structural point of view, the structures $\mathrm{K} 1$ and $\mathbf{K E}$ could be considered as a protonated keto form, where the coming acidic proton is delocalized and chelated between two neighbor carbonyl groups. It could be concluded that the protonation of $\mathbf{T - 7 0 5}$ leads to shift of the equilibrium from the enol to the keto tautomer.

\section{Conclusions}

Due to the lack of experimental data for the tautomerism of favipiravir, its tautomeric state was predicted by means of DFT calculations. The results have been validated by including 2-hydroxy pyridine and 2-hydroxy pyrazine, where experimentally determined tautomeric constants are available at variety of conditions, in the set of investigated compounds. According to the calculations, the enol tautomer is substantially more stable in the neutral T-705 and its analogue T-1105. Upon
Table 2 Relative energies* (M06-2X/def2TZVP) of the most stable protonated forms of T-705

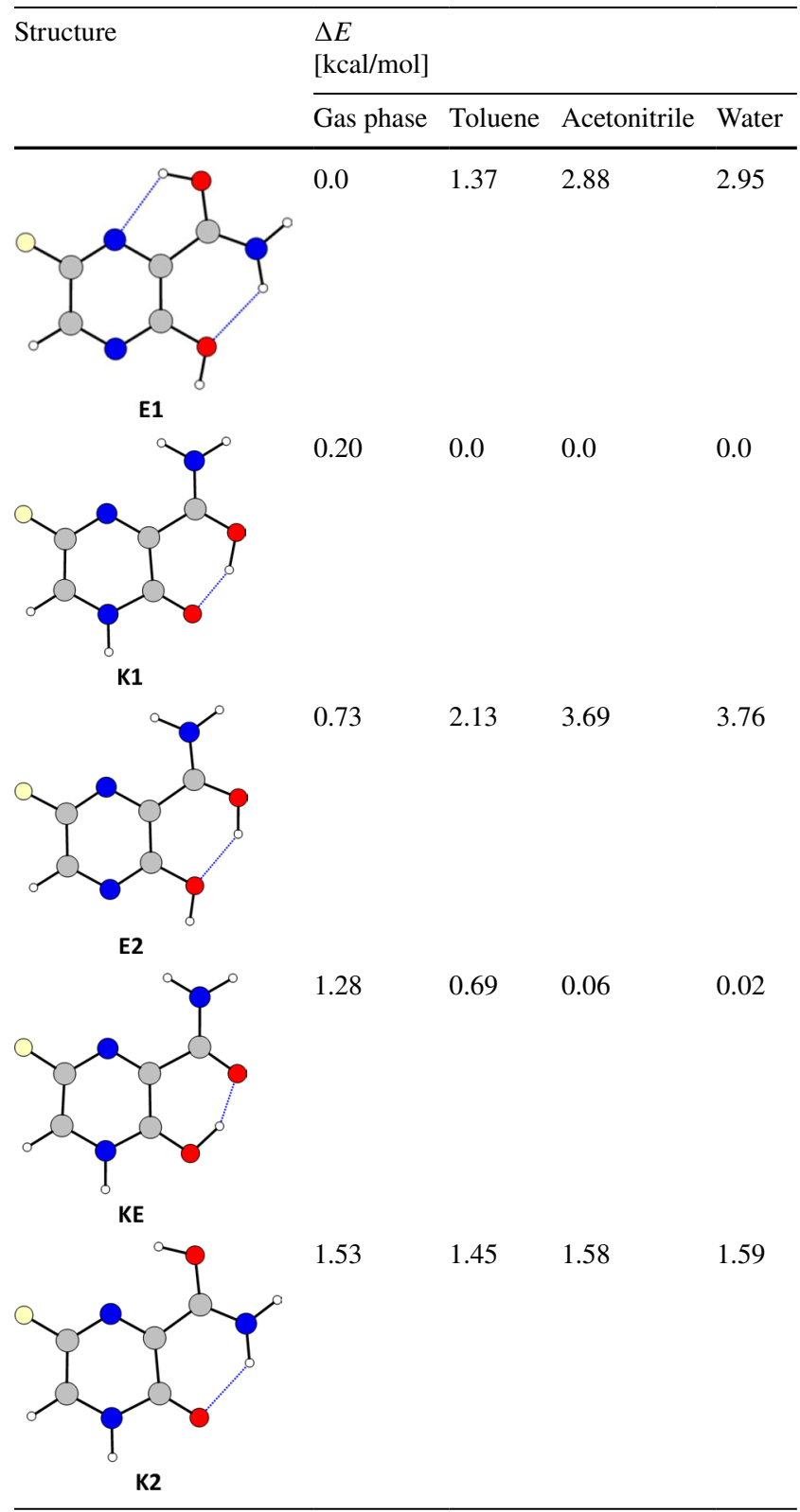

*Difference between total energies of the protonated compounds

acid addition, the equilibrium should be shifted to the keto tautomer. Of course the exact answer about the tautomerism of favipiravir and related compounds could be given by experimental studied. The corresponding investigations are in progress and will be reported. 


\section{Methodology}

Quantum chemical calculations were performed by using the Gaussian 09 D.01 program suite [48]. The M06-2X functional $[49,50]$ was used with def2TZVP [51] basis set. This fitted hybrid meta-GGA functional with 54\% HF exchange is specially developed to describe main-group thermochemistry and non-covalent interactions, showing very good results in prediction of the position of tautomeric equilibria [27-29, 52-54]. In addition, TautLYP [55], a specially optimized to predict the tautomerism in azodyes and Schiff bases, B3LYP-based functional, was used with 6-31++Gdp basis set. All structures were optimized in ground state without restrictions, using tight optimization criteria and ultrafine grid in the computation of two-electron integrals and their derivatives. Solvent effects are described using the Polarizable Continuum Model (PCM, the integral equation formalism variant, IEFPCM, as implemented in Gaussian 09) [56]. The true minima were verified by performing frequency calculations in the corresponding environment.

The relative stability of the tautomers was presented as difference between the total energies of the enol and keto forms $\left(\Delta E=E_{\mathrm{E}}-E_{\mathrm{K}}\right)$ in the corresponding solvent. A negative value indicates more stable enol form and vice versa.

Acknowledgements The access to the MADARA computer cluster for performing the calculations is gratefully acknowledged (Project RNF01/0110 by Bulgarian Science Fund).

\section{References}

1. Muller P (2009) Glossary of terms used in physical organic chemistry (IUPAC Recommendations 1994). Pure Appl Chem 66:1077-1184. https://doi.org/10.1351/pac199466051077

2. Taylor PJ, van der Zwan G, Antonov L (2013) Tautomerism: introduction, history, and recent developments in experimental and theoretical methods. In: Antonov L (ed) Tautomerism: methods and theories. Wiley, Weinheim, pp 1-24

3. Martin YC (2009) Let's not forget tautomers. J Comput Aided Mol Des 23:693-704. https://doi.org/10.1007/s10822-009-9303-2

4. Martin YC (2018) Experimental and pKa prediction aspects of tautomerism of drug-like molecules. Drug Discov Today Technol 27:59-64. https://doi.org/10.1016/j.ddtec.2018.06.006

5. Katritzky AR, Hall CD, El-Gendy BE-DM, Draghici B (2010) Tautomerism in drug discovery. J Comput Aided Mol Des 24:475-484. https://doi.org/10.1007/s10822-010-9359-z

6. Pospisil P, Ballmer P, Scapozza L, Folkers G (2003) Tautomerism in computer-aided drug design. J Recept Signal Transduct 23:361-371. https://doi.org/10.1081/RRS-120026975

7. Nagy PI (2016) Theoretical consideration of in-solution tautomeric equilibria in relation to drug design. In: Antonov L (ed) Tautomerism. Wiley-VCH Verlag GmbH \& Co. KGaA, Weinheim, pp 113-146

8. Milletti F, Storchi L, Sforna G et al (2009) Tautomer enumeration and stability prediction for virtual screening on large chemical databases. J Chem Inf Model 49:68-75. https://doi. org/10.1021/ci800340j

9. Guasch L, Yapamudiyansel W, Peach ML et al (2016) Experimental and chemoinformatics study of tautomerism in a database of commercially available screening samples. J Chem Inf Model 56:2149-2161. https://doi.org/10.1021/acs.jcim.6b003 38

10. Wahl O, Sander T (2020) Tautobase: an open tautomer database. J Chem Inf Model 60:1085-1089. https://doi.org/10.1021/acs. jcim.0c00035

11. Furuta Y, Takahashi K, Shiraki K et al (2009) T-705 (favipiravir) and related compounds: novel broad-spectrum inhibitors of RNA viral infections. Antiviral Res 82:95-102. https://doi. org/10.1016/j.antiviral.2009.02.198

12. Furuta Y, Komeno T, Nakamura T (2017) Favipiravir (T-705), a broad spectrum inhibitor of viral RNA polymerase. Proc Jpn Acad Ser B 93:449-463. https://doi.org/10.2183/pjab.93.027

13. Shiraki K, Daikoku T (2020) Favipiravir, an anti-influenza drug against life-threatening RNA virus infections. Pharmacol Ther. https://doi.org/10.1016/j.pharmthera.2020.107512

14. Odnovorov AI, Grebennikova TV, Pleteneva TV (2020) Specific influenza therapy: current state and prospects review. Syst Rev Pharm 9:83-91. https://doi.org/10.33380 12305-2066-2020-9-1-83-91

15. Furuta Y, Egawa H (2000) Nitrogenous heterocyclic carboxamide derivatives or salts thereof and antiviral agents containing both. Toyama Chemical Co., Ltd., Tokyo

16. Chen C, Huang J, Cheng Z et al (2020) Favipiravir versus arbidol for COVID-19: a randomized clinical trial. medRxiv. https://doi. org/10.1101/2020.03.17.20037432

17. Dong L, Hu S, Gao J (2020) Discovering drugs to treat coronavirus disease 2019 (COVID-19). Drug Discov Ther 14:58-60. https ://doi.org/10.5582/ddt.2020.01012

18. Niarchos N (2020) A drug developed to fight Ebola could hold hope for coronavirus treatment. Time. https://time.com/5814045/ ebola-drug-coronavirus-favipiravir/

19. Editorial (2020) The race against COVID-19. Nat Nanotechnol 15:239-240. https://doi.org/10.1038/s41565-020-0680-y

20. Sandoiu A (2020) Is the anti-flu drug Avigan effctive in treating COVID-19? Medical News Today. https://www.medicalnewstoda y.com/articles/anti-flu-drug-effective-in-treating-covid-19

21. Naesens L, Guddat LW, Keough DT et al (2013) Role of human hypoxanthine guanine phosphoribosyltransferase in activation of the antiviral agent T-705 (Favipiravir). Mol Pharmacol 84:615629. https://doi.org/10.1124/mol.113.087247

22. Furuta Y, Takahashi K, Kuno-Maekawa M et al (2005) Mechanism of action of T-705 against influenza virus. Antimicrob Agents Chemother 49:981-986. https://doi.org/10.1128/ AAC.49.3.981-986.2005

23. Jin Z, Smith LK, Rajwanshi VK et al (2013) The ambiguous basepairing and high substrate efficiency of T-705 (Favipiravir) Ribofuranosyl 5'-triphosphate towards influenza A virus polymerase. PLoS ONE 8:e68347. https://doi.org/10.1371/journal.pone.00683 47

24. Du Y, Chen X (2020) Favipiravir: pharmacokinetics and concerns about clinical trials for 2019-nCoV infection. Clin Pharmacol Ther. https://doi.org/10.1002/cpt.1844

25. Huchting J, Winkler M, Nasser H, Meier C (2017) Synthesis of T-705-ribonucleoside and T-705-ribonucleotide and studies of chemical stability. ChemMedChem 12:652-659. https://doi. org/10.1002/cmdc.201700116

26. da Silva G (2020) Protonation, tautomerism, and base pairing of the antiviral favipiravir (T-705). ChemRxiv. Preprint. https://doi. org/10.26434/chemrxiv.12229122.v2

27. Manolova Y, Deneva V, Antonov L et al (2014) The effect of the water on the curcumin tautomerism: a quantitative approach. 
Spectrochim Acta A Mol Biomol Spectrosc 132:815-820. https ://doi.org/10.1016/j.saa.2014.05.096

28. Ivanova D, Deneva V, Nedeltcheva D et al (2015) Tautomeric transformations of piroxicam in solution: a combined experimental and theoretical study. RSC Adv 5:31852-31860. https://doi. org/10.1039/C5RA03653D

29. Fabian WMF (2013) Quantum chemical calculation of tautomeric equilibria. In: Antonov L (ed) Tautomerism: methods and theories. Wiley-VCH Verlag GmbH \& Co. KGaA, Weinheim, pp 337-368

30. Carvalho AR (2019) Tautomeric equilibrium revisited: protontautomerism in solvent and the fundamentals of molecular stability prediction. ChemRxiv. Preprint. https://doi.org/10.26434/ chemrxiv.7699952.v3

31. Levin ES, Rodionova GN (1965) Tautomeric studies on lactams in the vapour state by infrared spectroscopy. Dokl Akad Nauk SSSR 164:910

32. Beak P, Fry FS (1973) Equilibrium between 2-hydroxypyridine and 2-pyridone in the gas phase. J Am Chem Soc 95:1700-1702. https://doi.org/10.1021/ja00786a078

33. Brown RS, Tse A, Vederas JC (1980) Photoelectron-determined core binding energies and predicted gas-phase basicities for the 2-hydroxypyridine.dblarw. 2-pyridone system. J Am Chem Soc 102:1174-1176. https://doi.org/10.1021/ja00523a050

34. Guimon C, Garrabe G, Pfister-Guillouzo G (1979) Spectroscopie photoelectronique a temperature variable equilibre prototropique des hydroxy-2 et mercapto-2 pyridines (). Tetrahedron Lett 20:2585-2588. https://doi.org/10.1016/S0040-4039(01)86355-3

35. Lapinski L, Nowak MJ, Fulara J et al (1992) Relation between structure and tautomerism in diazinones and diazinethiones: an experimental matrix isolation and theoretical ab initio study. J Phys Chem 96:6250-6254. https://doi.org/10.1021/j100194a030

36. Hatherley LD, Brown RD, Godfrey PD et al (1993) Gas-phase tautomeric equilibrium of 2-pyridinone and 2-hydroxypyridine by microwave spectroscopy. J Phys Chem 97:46-51. https://doi. org/10.1021/j100103a011

37. Nowak MJ, Lapinski L, Fulara J et al (1992) Matrix isolation IR spectroscopy of tautomeric systems and its theoretical interpretation: 2-hydroxypyridine/2(1H)-pyridinone. J Phys Chem 96:1562-1569. https://doi.org/10.1021/j100183a015

38. Neese F, Hansen A, Wennmohs F, Grimme S (2009) Accurate theoretical chemistry with coupled pair models. Acc Chem Res 42:641-648. https://doi.org/10.1021/ar800241t

39. Antonov L, Nedeltcheva D (2000) Resolution of overlapping UVVis absorption bands and quantitative analysis. Chem Soc Rev 29:217-227. https://doi.org/10.1039/a900007k

40. Antonov L (2013) Absorption UV-Vis spectroscopy and chemometrics: from qualitative conclusions to quantitative analysis. In: Antonov L (ed) Tautomerism: methods and theories. Wiley-VCH, Weinheim, pp 25-47

41. Beak P, Covington JB, Smith SG et al (1980) Displacement of protomeric equilibriums by self-association: hydroxypyridinepyridone and mercaptopyridine-thiopyridone isomer pairs. J Org Chem 45:1354-1362. https://doi.org/10.1021/jo01296a002

42. Frank J, Katritzky AR (1976) Tautomeric pyridines. Part XV. Pyridone-hydroxypyridine equilibria in solvents of differing polarity. J Chem Soc Perkin Trans 2:1428-1431. https://doi. org/10.1039/P29760001428
43. Forlani L, Cristoni G, Boga C et al (2002) Reinvestigation of the tautomerism of some substituted 2-hydroxypyridines. Arkivoc 2002:198. https://doi.org/10.3998/ark.5550190.0003.b18

44. Mason SF (1958) The tautomerism of $N$-heteroaromatic hydroxycompounds. Part III. Ionisation constants. J Chem Soc Resumed. https://doi.org/10.1039/jr9580000674

45. Taylor PJ (2013) The "basicity method" for estimating tautomer ratio: a radical re-appraisal. In: Antonov L (ed) Tautomerism: methods and theories. Wiley-VCH Verlag GmbH \& Co. KGaA, Weinheim, pp 305-335

46. Gerega A, Lapinski L, Nowak MJ et al (2007) Systematic effect of benzo-annelation on oxo-hydroxy tautomerism of heterocyclic compounds. experimental matrix-isolation and theoretical study. J Phys Chem A 111:4934-4943. https://doi.org/10.1021/jp070408j

47. Tobias S, Günther H (1982) Tautomerism in OH-, SH-, and $\mathrm{NH}_{2}$-substituted pyrazines-a carbon-13 and nitrogen-15 NMR study. Tetrahedron Lett 23:4785-4788. https://doi.org/10.1016/ S0040-4039(00)85713-5

48. Frisch MJ, Trucks GW, Schlegel HB et al (2013) Gaussian 09 Revision D.01. Gaussian Inc., Wallingford

49. Zhao Y, Truhlar DG (2008) Density functionals with broad applicability in chemistry. Acc Chem Res 41:157-167. https://doi. org/10.1021/ar700111a

50. Zhao Y, Truhlar DG (2008) The M06 suite of density functionals for main group thermochemistry, thermochemical kinetics, noncovalent interactions, excited states, and transition elements: two new functionals and systematic testing of four M06-class functionals and 12 other functionals. Theor Chem Acc 120:215-241. https://doi.org/10.1007/s00214-007-0310-x

51. Weigend F, Ahlrichs R (2005) Balanced basis sets of split valence, triple zeta valence and quadruple zeta valence quality for $\mathrm{H}$ to $\mathrm{Rn}$ : design and assessment of accuracy. Phys Chem Chem Phys 7:3297. https://doi.org/10.1039/b508541a

52. Kawauchi S, Antonov L (2013) Description of the tautomerism in some azonaphthols. J Phys Org Chem 26:643-652. https://doi. org/10.1002/poc. 3143

53. Tzvetkov NT, Stammler H-G, Hristova S et al (2019) (Pyrrolopyridin-5-yl)benzamides: BBB permeable monoamine oxidase $B$ inhibitors with neuroprotective effect on cortical neurons. Eur J Med Chem 162:793-809. https://doi.org/10.1016/j.ejmec h.2018.11.009

54. Manolova Y, Marciniak H, Tschierlei S et al (2017) Solvent control of intramolecular proton transfer: is 4-hydroxy-3-(piperidin1-ylmethyl)-1-naphthaldehyde a proton crane? Phys Chem Chem Phys 19:7316-7325. https://doi.org/10.1039/C7CP00220C

55. Antonov L (2019) Tautomerism in azo and azomethyne dyes: when and if theory meets experiment. Molecules 24:2252. https ://doi.org/10.3390/molecules24122252

56. Tomasi J, Mennucci B, Cammi R (2005) Quantum mechanical continuum solvation models. Chem Rev 105:2999-3094. https:// doi.org/10.1021/cr9904009

Publisher's Note Springer Nature remains neutral with regard to jurisdictional claims in published maps and institutional affiliations. 